\title{
Brinquedo terapêutico instrucional aplicado em crianças na utilização do cateter central de inserção periférica: percepção dos familiares
}

Instructional therapeutic toy used in children when using the peripherally inserted central catheter: family members' perception

Juguete terapéutico instructivo utilizado en niños cuando se usa el catéter central insertado periféricamente: percepción de los miembros de la familia

Ana Paula Alves Baltazar ${ }^{1}$ (D) https://orcid.org/0000-0003-0853-662X

Luana Tonin ${ }^{2}$ (D) https://orcid.org/0000-0003-3168-5762

Luciane Favero ${ }^{2}$ (D) https://orcid.org/0000-0002-4486-0032

Débora Maria Vargas Makuch ${ }^{1}$ (D) https://orcid.org/0000-0001-7060-4414

Ananda Rosa Borges ${ }^{1}$ (D) https://orcid.org/0000-0002-2968-9695

\section{Resumo}

Objetivo: Aplicar o brinquedo terapêutico instrucional em crianças hospitalizadas para inserção e manutenção do cateter central de inserção periférica e identificar a percepção dos familiares acerca da utilização do brinquedo terapêutico instrucional na inserção e manutenção do cateter central de inserção periférica.

Método: Pesquisa qualitativa, caracterizada como pesquisa-cuidado, realizada em unidades de internação de um hospital pediátrico no sul do Brasil. Participaram do estudo cinco crianças e cinco familiares cuidadores. Os dados foram coletados de junho a outubro de 2019 , utilizando o diário do pesquisador e a entrevista semiestruturada. As transcrições foram analisadas mediante análise temática.

Resultados: Foi possível constatar que o uso do brinquedo terapêutico instrucional, no preparo para inserção e manutenção do cateter central de inserção periférica, contribuiu para que as crianças ficassem mais calmas e tranquilas, além de cooperarem com a realização dos procedimentos.

Conclusão: A aplicação do brinquedo terapêutico instrucional neste contexto favoreceu para a aproximação e a comunicação efetiva entre os profissionais, a criança e o familiar, ampliando as possibilidades de realizar um cuidado atraumático.

\section{Abstract}

Objective: Apply the instructional therapeutic toy to hospitalized children for insertion and maintenance of the peripherally inserted central catheter and to identify the family members' perception about the use of the instructional therapeutic play in the insertion and maintenance of the peripherally inserted central catheter.

Method: Qualitative research, characterized as research-care, carried out in inpatient units of a pediatric hospital in southern Brazil. Five children and five family caregivers participated in the study. Data were collected from June to October 2019, using the researcher's diary and semi-structured interview. Transcripts were analyzed using thematic analysis.

Results: It was possible to verify that the use of the instructional therapeutic play, in the preparation for insertion and maintenance of the peripherally inserted central catheter, contributed for the children to be calmer and calm, in addition to cooperating with the procedures.

Conclusion: The application of the instructional therapeutic play in this context, favored the approach and effective communication between professionals, the child and the family, expanding the possibilities of performing atraumatic care.

\section{Resumen}

Objetivo: Aplique el juguete terapéutico instructivo a los niños hospitalizados para la inserción y el mantenimiento del catéter central insertado periféricamente e identificar la percepción de los miembros de la familia sobre el uso del juguete terapéutico instructivo en la inserción y mantenimiento del catéter central insertado periféricamente. Método: Investigación cualitativa, caracterizada como atención de investigación, realizada en unidades de hospitalización de un hospital pediátrico en el sur de Brasil. Cinco niños y cinco cuidadores familiares participaron en el estudio. Los datos se recopilaron de junio a octubre de 2019, utilizando el diario del investigador y la entrevista semiestructurada. Las transcripciones se analizaron mediante análisis temático.

Resultados: fue posible verificar que el uso del juguete terapéutico instructivo, en la preparación para la inserción y el mantenimiento del catéter central insertado periféricamente, contribuyó a que los niños estuvieran más tranquilos y tranquilos, además de cooperar con los procedimientos.

Conclusión: La aplicación del juguete terapéutico instructivo en este contexto, favoreció el enfoque y la comunicación efectiva entre profesionales, el niño y la familia, ampliando las posibilidades de realizar una atención atraumática.

\section{Como citar:}

Baltazar AP, Tonin L, Basegio LF, Makuch DM, Borges AR. Brinquedo terapêutico instrucional aplicado em crianças na utilização do cateter central de inserção periférica: percepção dos familiares. Rev Soc Bras Enferm Ped. 2020;20(2):87-96.

\section{Keywords}

Pediatric nursing; Nursing care; Central venous catheters; Play therapy

\section{Descriptores}

Enfermería pediátrica; Atención de enfermería; Catéteres venosos centrales; Juguete terapéutico 


\section{Introdução}

O brincar é essencial para a criança, esteja ela sadia ou doente, inclusive quando precisa ser hospitalizada. Diante deste contexto, deve ser compreendido como uma necessidade básica da criança e ser valorizado tanto quanto a higiene, alimentação, medicação e procedimentos. ${ }^{(1)}$

A inclusão do lúdico no ambiente hospitalar e no cuidado de enfermagem sofre barreiras, mas deve fazer parte da assistência humanizada como contribuição para o bem-estar dos pacientes e dos familiares que os acompanham. ${ }^{(2,3)}$ Pois, durante a hospitalização as crianças são submetidas a diferentes procedimentos dolorosos, sem entender o que está ocorrendo, com que finalidade e por que devem experimentá-las, gera sentimentos de medo, ansiedade e comportamento agressivo. ${ }^{(4,5)}$

Nesse sentido, destaca-se que os sentimentos adversos vivenciados por crianças submetidas a procedimentos invasivos durante a hospitalização podem interferir no curso de seu crescimento e desenvolvimento. ${ }^{(4)}$ Pais também experimentam sentimentos de ansiedade durante o período de hospitalização de seus filhos, e isto se deve principalmente pela falta de entendimento sobre os próximos procedimentos, familiaridade com o ambiente hospitalar e incerteza sobre a doença e tratamento de seus filhos. ${ }^{(6)}$

Para contribuir com a promoção de um cuidado humanizado, existem legislações que garantem que o brinquedo faça parte da rotina diária da criança em processo de hospitalização, tais como, a Lei ํํำ 11.104 de 21 de março de 2005, que dispõe sobre a obrigatoriedade de brinquedotecas em unidades de atendimento pediátrico em regime de internação. Também há a Resolução do Conselho Federal de Enfermagem (COFEN) nº 546/2017 no artigo $1^{\circ}$ que afirma que compete a equipe de enfermagem, que atua em pediatria, a utilização do Brinquedo Terapêutico (BT) na assistência à criança e família hospitalizadas. ${ }^{(7,8)}$

O BT consiste em uma estratégia de cuidado atraumático utilizado para auxiliar nas intervenções de enfermagem, e tem como intenção aproximar a criança do profissional de saúde, fornece orientações adequadas de acordo com a faixa etária, familiariza o infante e pais para o procedimento que será realizado..$^{(9,10)}$

Este instrumento pode ser classificado em três tipos: o brinquedo dramático que tem como finalidade permitir que a criança exteriorize seus sentimentos favorecendo aos profissionais identificar o que a está afligindo; o brinquedo instrucional que tem como função preparar e informar a criança quanto aos procedimentos pelos quais ela passará; e o brinquedo capacitador das funções fisiológicas que tem o objetivo de ensinar a criança a realizar o autocuidado e consiste em desenvolver atividades que facilitem esta condição. ${ }^{(11)}$

Dentro deste contexto, durante a hospitalização, a punção venosa é o procedimento no qual as crianças são mais comumente submetidas, para a coleta de amostras e administração de medicação intravenosa, ${ }^{(4)}$ por algumas vezes ocorre a necessidade da colocação do cateter central de inserção periférica (Peripherally Inserted Central Catheter, PICC) em crianças com a indicação de terapêutica medicamentosa por mais de sete dias, entre outras condições, ${ }^{(12)}$ este procedimento e vivência pode ser considerado como traumático para o infante e ainda desconhecido por parte dos pais e familiares. ${ }^{(13)}$

Considera-se que possam ser identificados vários estudos que abordam a temática do BT, (1-6,9-11) entretanto, não foram encontrados na literatura estudos dirigidos à inserção e manutenção de PICC. Diante do exposto, surgem as inquietações: Como se dá a utilização do BT instrucional na inserção e manutenção do PICC em crianças hospitalizadas? Qual a percepção dos familiares sobre a utilização do BT instrucional na inserção e manutenção do PICC?

Para tanto, este manuscrito tem como objetivo aplicar o BT instrucional na inserção e manutenção do PICC em crianças hospitalizadas e identificar a percepção dos familiares acerca da utilização do BT instrucional na inserção e manutenção do PICC.

\section{Métodos}

Trata-se de uma pesquisa qualitativa, caracterizada como uma pesquisa-cuidado. As etapas pertencentes ao método pesquisa-cuidado são: aproximação com o objeto de estudo; encontro com o ser pesquisado-cuidado; estabelecimento das conexões de pesquisa, teoria e prática; afastamento do ser pesquisador-cuidador e do ser pesquisado-cuidado e análise do apreendido. ${ }^{(14)}$

$\mathrm{Na}$ aproximação com o objeto de estudo, ocorreu preparo da pesquisadora principal para a coleta de dados, por meio da revisão da literatura, para iden- 
tificação do conhecimento na área e o resgate de referenciais utilizados na aplicação do BT, bem como discussões e treinamentos com a pesquisadora sênior. ${ }^{(14)}$

O encontro com o ser pesquisado-cuidado aconteceu nas unidades de internação de um hospital pediátrico localizado na região sul do Brasil, entre os meses de junho e outubro de 2019. Foi desenvolvido com crianças entre dois e seis anos de idade e seus respectivos familiares cuidadores, maiores de 18 anos, após assinatura do termo de assentimento e termo de consentimento do menor incapaz.

Como critérios de inclusão, foram delimitadas todas as crianças com indicação de inserção e/ou que necessitassem trocar o curativo do PICC; que estivessem internadas nas unidades de internação do hospital local do estudo e durante o período estabelecido para a coleta de dados; crianças com idade entre dois e seis anos completos.

Entre os familiares cuidadores, foram incluídos aqueles com idade superior a 18 anos que quisessem participar da pesquisa respondendo a um questionário semiestruturado por meio de entrevista áudio-gravada mediante autorização pelo termo de consentimento livre e esclarecido (TCLE).

Como critérios de exclusão estabeleceram-se: crianças que estivessem em precaução de contato, gotícula ou aerossóis por dificultar a higienização do brinquedo; e crianças com diagnóstico prévio de transtorno mental (solicitado pelo serviço de psicologia do hospital local do estudo). Quanto aos familiares cuidadores, foram excluídos aqueles que não preencheram os critérios de inclusão.

Na primeira etapa da coleta de dados foi utilizado o diário do pesquisador para descrever as expressões transmitidas pelas crianças antes, durante e após a utilização do BT instrucional na inserção e/ou manutenção do PICC. E na segunda etapa, os dados foram coletados mediante entrevista semiestruturada com perguntas abertas direcionadas aos familiares cuidadores sobre o perfil da criança e sua percepção em relação à utilização do BT na inserção e/ou manutenção do PICC.

A pesquisa passou por apreciação do Comitê de Ética e Pesquisa em Seres Humanos (CEP), sendo aprovada com Certificado de Apresentação para Apreciação Ética: 12954919.3.0000.5580, sob o parecer no 3.378.116, de 07 de junho de 2019, e com emenda aprovada pelo mesmo CEP sob o parecer no 3.577.999, em 16 de setembro de 2019.
Aos participantes, foram explicados os objetivos, a participação de caráter voluntário e solicitada a assinatura dos termos de consentimento e assentimento. Garantiu-se o anonimato dos participantes ao serem utilizados codinomes de personagens de desenho animado para identificar as crianças, tais como, Mônica, Magali, Cebolinha, Cascão e Chico Bento. Para os familiares cuidadores foi utilizado o grau de parentesco acrescido do nome do personagem escolhido, como por exemplo, mãe da Mônica.

O estabelecimento das conexões de pesquisa, teoria e prática, foi o momento em que ocorreu a interação entre pesquisador-cuidador e pesquisado-cuidado, em que a pesquisadora capta, desvela e ilumina o que deseja pesquisar, ao mesmo tempo em que observa e toma decisões em conjunto com o ser pesquisado. ${ }^{(14)}$

Nesta fase, ocorreu a aplicação do BT instrucional propriamente dito. A pesquisadora foi inserida no grupo de WhatsApp do time de acessos vasculares da instituição, no qual eram enviadas todas as solicitações de inserção de PICC. Com isso, verificavam-se as crianças que se encaixavam nos critérios de inclusão e a pesquisadora se direcionava ao setor em que o infante se encontrava hospitalizado.

Deste modo, primeiramente um representante do time de acessos conversava com o familiar explicando o procedimento de inserção do PICC, na sequência a pesquisadora o abordava para explicar os objetivos, riscos e benefícios da pesquisa, bem como o procedimento a ser realizado. Após o aceite deste, era também explicado para a criança, de acordo com o seu grau de entendimento, e então, a convidava para ouvir uma história e brincar com a pesquisadora.

O processo de aplicação do BT instrucional para a criança, no preparo para a inserção do PICC, ocorreu por meio de uma contação de história (Apêndice 1), explicando o procedimento que seria realizado por meio de um boneco estruturado (boneco de borracha), bem como os materiais que seriam usados para tal (fita métrica, máscara, touca, avental, clorexidina alcóolica, luvas, compressa de gaze, seringas, soro fisiológico, cateter PICC, pedaços de tecido, pinça anatômica e curativo filme transparente).

A aplicação do BT instrucional ocorreu 30 minutos antes da inserção do PICC, e o familiar acompanhou todo o processo até o término do procedimento. A demonstração no boneco sucedeu concomitante a 
contação da história realizada pela pesquisadora, neste momento a criança apenas observava. Ao término, era dada a oportunidade para ela brincar com o boneco e demonstrar o que tinha acontecido de maneira livre. Cada criança recebeu uma sessão de BT instrucional, com duração de em média 20 minutos.

Quanto à manutenção do PICC, e de acordo com o protocolo da instituição, o curativo deve ser trocado a cada sete dias enquanto íntegro, ou antes, se presença de sujidade ou descolamento da película. Nesta fase, cada criança recebeu uma sessão de BT instrucional, com duração média de 15 minutos.

Para a aplicação do BT instrucional no preparo da manutenção do PICC também foi usado a contação de história, explicando o procedimento que seria realizado por meio do boneco estruturado (boneco de borracha), bem como os materiais que seriam utilizados para tal (máscara, clorexidina alcóolica, luvas, compressa de gaze, pinça anatômica e curativo transparente).

Após a utilização do BT pela pesquisadora, o(a) enfermeiro(a) do time de acessos vasculares realizava o procedimento de inserção do PICC e a etapa de manutenção do dispositivo, especificamente a troca do curativo, era realizada pela pesquisadora.

Assim, no período de junho a outubro, 46 crianças tinham indicação para inserção de PICC na faixa etária de dois a seis anos de idade. Entretanto, destes, seis receberam alta hospitalar, em oito casos houve o cancelamento da inserção de PICC, para cinco crianças o familiar cuidador recusou o procedimento, quatro inseriram cateter venoso central duplo lúmen e dois não tinham condições venosas para colocação do dispositivo. Resultando em um número de 21 crianças que realizaram o procedimento. Após aplicação dos critérios de inclusão (já descritos anteriormente), 16 crianças estavam em precaução de contato, gotículas e/ou aerossóis não preenchendo aos critérios, com isso, totalizaram 10 participantes da pesquisa, cinco crianças e cinco familiares cuidadores.

Por conseguinte, os materiais utilizados na coleta de dados foram compostos pelo diário do pesquisador referente à aplicação do BT instrucional com a criança, registrados pela pesquisadora ao término de cada sessão, e pela entrevista semiestruturada aplicada aos familiares cuidadores.

O afastamento do ser pesquisador-cuidador e do ser pesquisado-cuidado configurou o término da re- lação estabelecida no processo pesquisa-cuidado e foi preparada durante toda a trajetória da pesquisa, para que, ao final dos encontros, os seres pesquisados-cuidado estivessem prontos para o afastamento do ser pesquisador-cuidador. ${ }^{(14)}$

Para a análise do apreendido foi escolhida a técnica de análise temática de conteúdo: a pré-análise englobou a leitura compreensiva e exaustiva do material selecionado, buscando indicadores que orientaram a interpretação final; a exploração do material consistiu na codificação do material coletado, classificando e categorizando os dados em categorias que comandaram a especificação dos temas; e para o tratamento dos resultados, buscou-se por meio da interpretação, a comparação das informações com as existentes na literatura. ${ }^{(15)}$

\section{Resultados}

Compondo o que se denomina caracterização inicial, tem-se a idade, gênero e patologia das crianças participantes do estudo. Quanto à idade, as crianças tinham dois, quatro, seis, cinco e dois anos de idade. $O$ gênero masculino predominou com três crianças. Em relação à patologia, Mônica tem mielomeningocele; Cebolinha internou com quadro de anemia e febre a esclarecer; Cascão tem leucemia linfoblástica aguda, Chico Bento tem neoplasia maligna do tecido conjuntivo e tecidos moles da pelve; e Magali internou com quadro de espondilodiscite. Dentre os cinco familiares cuidadores, todas eram mães das crianças atendidas. Após a análise dos instrumentos de coleta de dados e seguindo os passos preconizados pela análise temática proposta, considerando os momentos de inserção e manutenção do PICC para a utilização do BT instrucional, emergiram duas categorias: Brinquedo terapêutico para o enfrentamento de situações dolorosas; e Interação da criança com o brinquedo terapêutico: lugar de calma e segurança, as quais serão apresentadas a seguir e posteriormente discutidas com embasamento na literatura vigente.

\section{Brinquedo terapêutico para o enfrentamento de situações dolorosas}

Em relação à aplicação do BT na inserção do PICC, observou-se que os familiares cuidadores referem que este instrumento é importante para que a criança 
esteja preparada e saiba o que acontecerá com ela, e também para que eles possam aceitar os procedimentos com mais facilidade. Conforme demonstrados nas falas a seguir:

"[...] Eu percebo assim, tudo o que a gente explica para ela, ela aceita com mais facilidade [...]." Mãe da Mônica.

"[...] Foi bom para preparar ele para conseguir vir até a sala (de procedimentos) [...] Então eu achei que foi muito importante para ele ter ciência do que poderia acontecer né [...] Foi interessante para ele entender o procedimento que iria ocorrer com ele [...]." Mãe do Cebolinha.

Além disso, nas falas a seguir, nota-se que o uso do BT instrucional é extremamente relevante para que as crianças se sintam mais seguras em relação ao procedimento que será submetida.

"Ah, eu achei interessante, porque com isso a criança, parece que elas ficam mais seguras de você estar explicando [...]." Mãe da Mônica.

"Eu acho que daí ele fica menos assustado [...] Já foi sabendo como que ia ser né." Mãe do Cascão.

No que diz respeito à reação da criança ao utilizar um brinquedo antes do procedimento, percebe-se que elas gostam de brincar, de estar em contato e de ajudar a cuidar do boneco. Além do mais, ficam mais calmas, conforme descritos nos relatos abaixo:

"Eu achei que ela ficou mais calma [...] No caso assim, ela usa bolsinha de colostomia, tem mitrofanoff, dai também a gente faz isso na boneca dela [...] Então com isso ela se acalma mais e entende mais assim o que está acontecendo com ela mesmo." Mãe da Mônica.

"[...] Eu percebi que ele participou, que ele brincou, que ele gostou [...] Então, ele gostou de estar em contato com a criança (boneco) né [...] Deu um nominho para ele e tudo, então eu percebi que houve assim um interesse dele em dar um nome, em cuidar, em saber o que era [...]." Mãe do Cebolinha.

"Percebi durante a aplicação do brinquedo terapêutico instrucional a preocupação da criança em saber se no mo- mento da punção a "Manu" ia sentir dor (nome escolhido para a boneca). Na inserção do PICC notei que a criança chorou apenas na punção venosa, mantendo-se calma na realização do procedimento. Após o término, me questionou se a "Manu" já tinha melhorado e recebido alta hospitalar". Diário de campo - Mônica (2 anos).

Os familiares cuidadores foram questionados se a criança já havia passado pelo procedimento de inserção do PICC anteriormente e como tinha sido a experiência, porém apenas a mãe da Mônica relatou que sua filha passou pelo procedimento.

"Já, mas quando ela era bem menorzinha, então acho que ela nem se recorda assim sabe." Mãe da Mônica.

No entanto, ao serem questionados se as crianças passaram por algum procedimento semelhante, eles descrevem situações anteriores de punção venosa para coleta de exames e infusão de medicamentos, como pode-se observar nas falas a seguir:

"Ela ficou bem agitada, bem nervosa, e às vezes as pessoas que vão fazer o procedimento (punção venosa) com ela, não chega nem a conversar com ela mesmo, então dai ela fica bem irritada mesmo sabe." Mãe da Mônica.

"[...] Ele só tinha feito retirada de sangue para exames [...] Foi bem tranquilo, a gente falou para ele que ele tinha que ser corajoso, que era para avaliar o sangue dele, e ver se estava tudo bem, então assim, foi bem tranquilo até durante a preparação né, é claro na picada ele chorou, mas depois foi só um pouquinho e ele já parou [...]" Mãe do Cebolinha.

Já com relação ao sentimento da criança após a aplicação do BT instrucional, os familiares cuidadores referem que eles ficam mais seguros e tranquilos. Além de ser menos confuso quando alguém explica antes o que será realizado, como descrito nas falas abaixo:

"Acho que ele ficou mais tranquilo né, você já tinha explicado tudo certinho para ele [...]." Mãe do Cascão.

"[...] Eu achei assim, que ela se sentiu segura [...] É menos confuso para a cabecinha deles né, tipo, faz com 
a boneca e faz comigo também depois né." Mãe da Mônica.

"[...] Apesar de ter sido difícil aqui na hora de colocar (inserir o PICC), que ele ficou nervoso, ele está bem tranquilo agora, foi bem legal." Mãe do Cebolinha.

"Na inserção do PICC, chorou na hora da punção venosa, e pude perceber um olhar de assustado durante a realização do procedimento. Quando eu conversava com a criança, a mesma demonstrou confiança e se sentiu mais seguro." Diário de campo - Cascão (6 anos).

Dessa forma, entende-se que a utilização do BT instrucional no preparo para a inserção do PICC é benéfica, pois as crianças passam a aceitar melhor o procedimento, ficam mais calmas e tranquilas, e se sentem mais seguras. Com isso, facilita a realização dos procedimentos de enfermagem e contribui para uma assistência atraumática.

\section{Interação da criança com o brinquedo terapêutico: lugar de calma e segurança}

Após a inserção do PICC, é necessário realizar a manutenção do cateter e dentre os cuidados de enfermagem se destaca a troca do curativo. No que diz respeito à aplicação do BT instrucional nesse momento, os familiares cuidadores relatam que é interessante porque a criança presta atenção no que acontece com o boneco e não fica com tanto medo quando for realizado nela.

"É, eu acho super interessante assim para a criança que ela presta atenção [...] O curativo, feito a limpeza, né, e ela olha detalhes do boneco e possivelmente ela imagina ali uma outra criança, dai eu achei bom." Mãe do Chico Bento.

"Ah, eu acho que é bom né!? Porque dai a criança ali, já está vendo, e [...] não vai ficar com tanto medo." Mãe do Magali.

Em relação à reação da criança ao utilizar um brinquedo antes da troca de curativo do PICC, foi referido que os infantes gostaram de interagir com o boneco, além de ficarem mais animados e tranquilos, mesmo no início ter ficado um pouco assustado.
"Do início eu percebi o olhar dele um pouco assustado, num nível mínimo [...] Mas aí eu vi que ele gostou, que ele começou a interagir com o boneco daí." Mãe do Chico Bento.

"Ah ela gostou né, ela ficou bem animadinha (risos), deu uma tranquilizada né, porque ela é bem agitada." Mãe da Magali.

"No momento de retirada da película transparente (curativo), criança demonstrou-se um pouco agitada e chorosa. Na limpeza e aplicação da nova película, estava mais calma e colaborou com o término do procedimento." Diário de campo - Chico Bento (5 anos).

Ao serem questionados se a criança já havia passado pela troca de curativo do PICC anteriormente e como foi a experiência, podemos observar nos relatos que as crianças choravam um pouco mais, gritavam, mordiam, apresentavam maior irritabilidade e até mesmo não deixavam que ninguém se aproximasse delas.

"Ele sempre grita, porque dói um pouco ali a fita para puxar né, que diz que puxa o pelo, o adesivo ele fala, o adesivo puxa." Mãe do Chico Bento.

"Antes do boneco ele chorava um pouco mais, ele gritava né, não deixava ninguém ficar perto dele [...] ele esperneava [...]." Mãe do Chico Bento.

"Trocar o curativo do PICC sim. Ah ela grita bastante, esperneia, morde (risos) [...] Antes ela ia chorando, ela ficava bem irritada, gritando e chorando, e ia para o quarto chorando [...]." Mãe da Magali.

"Nas trocas anteriores do curativo, criança mordia e chutava o profissional que realizava o procedimento. Foi possível observar que durante a retirada da película transparente, a criança estava agitada e chorando, e no decorrer do procedimento foi se tranquilizando e acalmando. Ao término, já começou a brincar com sua boneca e retornou para o quarto sorrindo e cantando." Diário de campo - Magali (2 anos).

Assim, após a aplicação do BT instrucional na troca de curativo do PICC, foi possível perceber com as falas que mesmo que a criança ainda tivesse com um 
pouco de medo, elas não gritavam tanto como em situações anteriores, choraram um pouco menos, e até estavam mais calmas e seguras.

"[...] Eu ainda não vi um melhoramento sobre isso, porque eu acho talvez que com algumas outras vezes né [...] para ele ir entendendo ali [...] Mas de primeiro momento [...] ele ainda teve medo, foi um pouco menos, porque ele não ficou gritando tanto assim como das outras vezes [...] talvez ali em mente ele começou a lembrar do boneco que era simples a troca (do curativo) né." Mãe do Chico Bento.

"Ah dai ela deu uma acalmada, só que ela é agitada assim né, mas acalmou, foi bom [...] Agora ela tá calma, ela não chorou, esperneou um pouco, mas não foi bastante né, foi pouco." Mãe da Magali.

Diante do exposto, nota-se que no momento de retirada da película transparente, as crianças choravam pelo fato da dor, mas na realização da antissepsia da inserção do cateter e oclusão com nova película, eles passaram a ser mais colaborativos.

\section{Discussão}

A partir da análise dos resultados apresentados foi possível constatar que o uso do BT instrucional, no preparo para inserção e manutenção do PICC, contribuiu para que as crianças ficassem mais calmas e tranquilas, além de cooperar com a realização dos procedimentos. Apesar de ainda existir o medo e a irritabilidade em certos momentos, o brinquedo ajudou a minimizar essas reações conforme descrito nos relatos dos familiares cuidadores e diário do pesquisador.

Permitir a participação de crianças em jogos terapêuticos durante a internação hospitalar, melhora a comunicação terapêutica, auxilia na adaptação a este ambiente, promove o alívio da dor e da ansiedade e aumenta a adesão aos procedimentos hospitalares..$^{(5,16)}$ Brincar é um escudo contra as ameaças percebidas pelas crianças, o que propicia o enfrentamento desta situação adversa e a habilidade de resiliência. ${ }^{(16,17)}$

Quando as crianças têm a oportunidade de brincar com os materiais utilizados nos procedimentos aos quais serão submetidas posteriormente, elas têm a chance de esclarecer suas dúvidas e curiosidades, e podem compreender a necessidade daquele procedimento, o que proporcionará a redução dos sentimentos de medo. ${ }^{(18,19)}$

Quando se utiliza o BT para o preparo aos procedimentos, os comportamentos de agressividade são praticamente inexistentes, pois a terapêtica com o brinquedo possibilita a amenização dos sentimentos de insegurança, ansiedade e medo, aumenta a sua cooperação, e ainda proporciona uma assistência atraumática frente aos procedimentos considerados dolorosos. ${ }^{(4,5,17)}$

Em um estudo, após a sessão com o BT, as crianças com idade entre quatro e seis anos, público-alvo também desta pesquisa, passaram a aceitar melhor os procedimentos e os acompanhantes reconheceram a importância da terapêutica com o brinquedo como contribuição para melhoria desse processo. ${ }^{(20)}$

Além disso, o uso rotineiro do BT permite que a criança antecipe eventos causados por um futuro incerto, o que possibilita o enfrentamento das tensões e ansiedades presentes em situações desconhecidas por elas, como por exemplo, a punção venosa. ${ }^{(4,19)}$ Pesquisa evidenciou que o uso de BT influenciou significativamente os escores de dor em crianças hospitalizadas submetidas a procedimentos invasivos, dentre eles a punção venosa, com $60,9 \%$ da amostra relatando que a dor diminuiu após a conclusão das sessões de BT. ${ }^{(4)}$

Cabe salientar que a dor tem um impacto negativo no desenvolvimento cerebral das crianças, sobretudo àquelas que são submetidas constantemente a procedimentos dolorosos; estudo aponta que o manejo inadequado da dor na primeira infância resultou em limiares mais baixos de dor à medida que estes indivíduos envelhecem. ${ }^{(17)}$ As sessões de BT não se destinam a suplantar a sensação dolorosa, mas configuram uma excelente ferramenta não farmacológica de manejo da dor. ${ }^{(4)}$

Quando submetidas às sessões com o BT as crianças reagem melhor, como no momento da troca de curativo e fixação do dispositivo intravenoso, em que demonstram menos medo, ansiedade e tensão. Além disso, este instrumento é extremamente importante, pois é uma forma de humanizar o ambiente hospitalar, diminuir o trauma causado pelo procedimento doloroso de punção venosa, trauma este que pode acompanhar a criança em todos os cuidados subsequentes de manutenção do dispositivo, e ainda reduzir o tempo 
da assistência de enfermagem, uma vez que a criança passa a cooperar mais. ${ }^{(18-20)}$

O BT instrucional possui inúmeros benefícios tanto para a criança, como para os familiares que os acompanham e os profissionais de saúde, afirma um estudo. Dentre eles, destacam-se a melhora do relacionamento entre os envolvidos (criança, família e profissional), contribuição para a redução do estresse decorrente do processo de hospitalização, melhora da compreensão e aceitação da criança com relação aos procedimentos, ajuda a estimular a criança a manter sua capacidade física, e ainda, diminui a hostilidade do ambiente. ${ }^{(6)}$

Além disso, a participação dos pais na intervenção terapêutica lúdica, aumenta o seu conhecimento e entendimento sobre procedimentos em contexto hospitalar, o que pode contribuir para a redução da ansiedade, o que seria benéfico para as crianças, visto que pais menos ansiosos podem ajudar os filhos a lidarem melhor com esta situação. ${ }^{(6)} \mathrm{A}$ inclusão dos pais oportuniza o seu envolvimento no cuidado aos filhos e incentiva o cuidado centrado na família, abordagem esta que pressupõe a individualidade e a integralidade do cuidado. ${ }^{(17)}$

O uso do BT é uma intervenção relevante na prática cotidiana das equipes de saúde em unidades pediátricas, principalmente para a equipe de enfermagem, contudo tal prática deve ser realizada de forma sistemática, pautada em protocolos validados. ${ }^{(4)} \mathrm{O}$ BT é uma intervenção de enfermagem a ser incorporada no plano de cuidados ao paciente pediátrico, entretanto o dimensionamento de pessoal de enfermagem inadequado para o cuidado pediátrico, é um dos fatores que impacta na horizontalidade e na integralidade do cuidado, além da formação do profissional carecer de aproximação com esta temática. ${ }^{(2)}$

Para o uso efetivo e sistemático do BT, há de se promover capacitações iniciais e periódicas para os profissionais de enfermagem ${ }^{(4)}$ quanto à humanização e ao uso deste instrumento, além de conscientizar e estimular os profissionais a serem mais reflexivos e mostrar que a sua práxis traz benefícios para a equipe, criança e família.

Como limitação do estudo destaca-se o número reduzido de participantes em decorrência da restrição da amostra e devido ao curto período de tempo destinado a coleta de dados. Portanto, faz-se necessário investir na realização de novos estudos a fim de atingir um número maior de participantes, bem como sensibilizar e conscientizar os profissionais de enfermagem para que adotem a estratégia do BT no cuidado à criança e família hospitalizadas, tendo em vista as vantagens proporcionadas por esse instrumento.

\section{Conclusão}

Ao analisar a reação da criança e a percepção dos familiares cuidadores participantes desta pesquisa na utilização do BT instrucional para a inserção e manutenção do PICC, concluiu-se que este instrumento possui inúmeros benefícios, tais como, preparação da criança para o procedimento com maior aceitação, colaboração do infante para a realização da assistência de enfermagem por compreender o que será realizado e, ainda, contribuição para a formação de vínculo e comunicação efetiva entre criança, família e profissional. Os familiares expressaram sentimentos positivos relacionados ao uso do BT instrucional. Conseguiram perceber a diferença das respostas da criança com o uso do instrumento, sendo essas positivas e consideraram que essa prática é importante no cuidado a criança hospitalizada. Ademais, observou-se que, com o uso do BT instrucional, as crianças demonstraram sentimentos de segurança e tranquilidade, redução dos comportamentos de irritabilidade, agressividade, agitação e medo do que antes era considerado desconhecido por eles. Com isso, torna-se indispensável a implantação desta ferramenta na prática assistencial de enfermagem. No entanto, apesar de constatarmos que a utilização do BT instrucional é eficaz no preparo para inserção e manutenção do PICC, é imprescindível que os profissionais de enfermagem estejam treinados e capacitados para implantar a prática do seu uso na assistência à criança e família hospitalizadas.

\section{Contribuições}

Baltazar APA, Tonin L, Basegio LF, Makuch DMV e Borges AR declaram que contribuíram com a concepção do estudo, análise e interpretação dos dados, revisão crítica relevante do conteúdo intelectual e aprovação da versão final a ser publicada. 


\section{Referências}

1. Maia EB, Ohara CV, Ribeiro CA. Ensino do brinquedo terapêutico na graduação em enfermagem: ações e estratégias didáticas utilizadas por professores. Texto Contexto Enferm. 2019;28:e20170364.

2. Aranha BF, Souza MA, Pedroso GE, Maia EB, Melo LL. Utilizando o brinquedo terapêutico instrucional durante a admissão de crianças no hospital: percepção da família. Rev Gaúcha Enferm. 2020;41:e20180413.

3. Souza $\mathrm{AA}$, Figueiredo ML, Prado PF, Souto SG. Uso de recursos lúdicos na assistência à criança hospitalizada: relato de experiência. Rev Intercâmbio. 2017;10:238-43.

4. Lemos IC, Silva LG, Delmondes GA, Brasil AX, Santos PL, Gomes EB, et al. Therapeutic play use in children under the venipuncture: a strategy for pain reduction. Am J Nurs Res. 2016;4(1):1-5.

5. Kapkın G, Manav G, Muslu GK. Effect of Therapeutic Play Methods on Hospitalized Children in Turkey: A Systematic Review. Erciyes Med J. 2020;42(2):127-31.

6. He HG, Zhu LX, Chan WC, Liam JL, Ko SS, Li HC, et al. A mixed-method study of effects of a therapeutic play intervention for children on parental anxiety and parents' perceptions of the intervention. J Adv Nurs. 2015;71(7):1539-51.

7. Brasil, Leis, Decretos. Lei $n^{0} 11.104$ de 21 de março de 2005. Dispõe sobre a obrigatoriedade de instalação de brinquedotecas nas unidades de saúde que ofereçam atendimento pediátrico em regime de internação 25 mar 2005. Disponivel em: http:// www.planalto.gov.br/ccivil_03/_At02004-2006/2005/Lei/L11104.htm.

8. Conselho Federal de Enfermagem (COFEN). Resolução COFEN 546/2017 de 09 de maio de 2017. Dispõe sobre a utilização de técnica de brinquedo terapêutico pela enfermagem. Diário Oficial da União. Brasília (DF): COFEN; 2017. Disponível em: http://www.cofen.gov. br/resolucao-cofen-no-05462017_52036.html.

9. Berté C, Ogradowski KR, Zagonel IP, Tonin L, Favero L, Almeida Junior RL. Brinquedo terapêutico no contexto da emergência pediátrica. Rev Baiana Enferm. 2017;31(3):e20378.
10. Gomes MF, Silva ID, Capellini VK. Conhecimento dos profissionais de enfermagem sobre a utilização do brinquedo no cuidado as crianças hospitalizadas. Rev Enferm UFPI. 2016;5(1):23-7.

11. Fontes CM, Mondini CC, Moraes MC, Bachega MI, Maximino NP. Utilização do brinquedo terapêutico na assistência à criança hospitalizada. Rev Bras Ed Esp. 2010;16(1):95106.

12. Infusion Nurses Society Brasil. Diretrizes práticas para terapia infusional. 3a ed. São Paulo: Athena Editora; 2018. p. 127.

13. Souza AM. Protocolo assistencial para inserção e manutenção de picc em uma unidade de terapia intensiva neonatal [Monografia]. Florianópolis: Universidade Federal de Santa Catarina; 2014.

14. Zagonel IP, Neves EP, Marques KM, Iamin SR, Victor LS. Pesquisa-cuidado: da teoria à prática. In: Lacerda MR, Costenaro RGS. Metodologias da pesquisa para a enfermagem e saúde da teoria à prática. Porto Alegre: Editora Moriá; 2016. p. 215-28.

15. Minayo MC, Deslandes SF, Gomes R. Pesquisa social: teoria, método e criatividade. 31a ed. Petrópolis: Editora Vozes; 2012.

16. Ullan AM, Belver MH. Play as a source of psychological well-being for hospitalized children: study review. Int Ped Chi Care. 2019;2(1):92-8.

17. Drape K, Greenshields S. Using play as a distraction technique for children undergoing medical procedures. Br J Nurs. 2020;29(3):142-3.

18. Canêz JB, Gabatz RI, Hense TD, VazVG, Marques RS, Milbrath VM. 0 brinquedo terapêutico no cuidado de enfermagem à criança hospitalizada. Rev Enferm Atual In Derme. 2019;88(26).

19. Caleffi CC, Rocha PK, Anders JC, Souza AI, Burciaga VB, Serapião LS. Contribuição do brinquedo terapêutico estruturado em um modelo de cuidado de enfermagem para crianças hospitalizadas. Rev Gaúcha Enferm. 2016;37(2):e58131.

20. Gomes AC, Silva AT, Santos CM, Palermo TA. Brinquedo terapêutico no alívio da dor em crianças hospitalizadas. Perspectivas Online: Biológicas \& Saúde. 2019;29(9):33-42.

Apêndice 1. História utilizada para explicar a inserção e manutenção do PICC, durante a sessão do brinquedo terapêutico instrucional.

Olá, (nome da criança)* Vamos explicar para você o que viemos fazer, contando a história da Manu, uma menina de 3 anos e de sua mãe Bia.

Certo dia Manu acordou triste, desanimada, sem vontade de comer e brincar, com dor e febre. Bia ficou muito preocupada com sua filha, pois Manu é uma criança bastante esperta, e por isso decidiu levá-la ao hospital. Chegando ao hospital, Manu foi examinada pelo médico, o qual disse que ela precisaria ficar internada para tomar remédio na veia por alguns dias para melhorar. Então, as duas foram encaminhadas para o quarto onde ficariam. Quando chegaram ao quarto, uma enfermeira foi examinar Manu, e conversar com ela e sua mãe. Como Manu precisaria receber remédio na veia por vários dias, a enfermeira disse que ela precisaria colocar um PICC (que é um cateter comprido que dura bastante tempo), e assim, evitaria ficar levando muitas picadinhas. Após a conversa, Bia foi explicar para Manu como seria colocado o PICC para receber o remédio:

- Manu, primeiro a enfermeira vai precisar pegar uma veia com um cateter (caninho) pequeno, ela vai pedir para você esticar o braço, apertá-lo um pouco com este garrote que é uma borracha para ver a sua veia. Depois, vai limpar a pele com algodão e álcool, e você não vai poder mexer o braço para pegar a veia. Se não conseguir pegar sua veia na primeira picada, vai precisar furar de novo. Vai doer um pouco na hora da picada, mas vai passar assim que pegar a veia. Então, a enfermeira, vai tirar o garrote de seu braço, conectar a seringa no cateter e depois abrir a torneirinha para $\mathrm{o}$ remédio entrar para seu corpo, prender o cateter com uma fitinha, colocar uma atadura e outro esparadrapo para que o cateter não saia da veia.

- A mamãe vai ficar com você o tempo todo ao seu lado. Pode chorar se quiser, só não pode mexer o seu braço.

- Com esse remédio entrando no seu corpo, você vai dormir um pouquinho para que a enfermeira possa inserir (colocar) o PICC no seu braço (ou pescoço).

- Para colocar o PICC vai ser bem parecido com o cateter de antes, só que você não vai sentir dor, mas pode se sentir um pouco incomodado. A enfermeira vai precisar pegar outra veia com um cateter (caninho) mais comprido, ela vai esticar seu braço e apertá-lo um pouco com a borracha para ver a sua 
veia. Depois, vai limpar a pele, pouco parecido como antes, e você não vai poder mexer o braço para pegar a veia. Se não conseguir pegar sua veia na primeira picada, vai precisar furar de novo. Então, a enfermeira, vai tirar o garrote de seu braço, colocar o caninho comprido na sua veia, conectar o equipo e depois abrir a torneirinha para o remédio entrar para seu corpo, prender com uma fitinha transparente para que o PICC não saia da veia.

- Quando você acordar, já vai ter acabado.
- Vai ser preciso trocar o curativo transparente uma vez por semana, ou quando ele estiver sujo/ molhado para que não entre bichinhos (microorganismos) no seu corpo.

Manu tomou o remédio todos os dias, então a enfermeira retirou o PICC, quando ela sarou e pode ir embora para casa com sua mãe Bia.

* Os nomes fictícios da história sofreram alterações de acordo com o sexo da criança. 